missiles for space vehicles, up to speeds of say Mach 4, might considerably reduce the weight at launch and the rocket thrust required. Another notable contribution comes from J. H. Laning, jun., and others, who describe a design study for a vehicle to go near Mars, to photograph it, and to return.

The third group of papers records a discussion panel on the question "What use is man in space?" The answer given by almost all the speakers was : "not much use at all". But the U.S. Air Force chairman stoutly resisted this undermining of the Symposium's raison d'être by saying that man will, nevertheless, go into space.

The fourth and most controversial group of papers is concerned with the Moon. First, T. Gold argues persuasively that the Moon's surface is deeply covered in dust: "the top few feet may well be extremely loose and more treacherous than quick. sand". Then F. L. Whipple, just as persuasive, contends that the dust must cement "into a weak, porous matrix" under the bombardment of meteorites, corpuscular radiation, etc. Finally comes G. P. Kuiper, whose paper is the most striking in the book, since it contains twenty-three magnificent photographs of the Moon, mostly full-page : after surveying the lunar topography in detail, Dr. Kuiper finds "overwhelming evidence that the traditional view that the mare floors are lava fields is correct"- - a rebuff for the dust-men.

These technical papers, which take up most of the book, form a valuable record; but the same cannot be said for the introductory material, which often sounds too nationalistic a note. Nor is the editing perfect : for example, a three-line footnote on p. 139 has somehow escaped the deletion it obviously deserves, and the grouping of the contributions is not entirely logical, since the solitary paper on "Space Navigation" appears in the section entitled "Control and Propulsion...", and not in the section on "Departure, Space Navigation and Re-entry", which would seem to be its proper home.

\section{G. KING-HELE}

\section{PLANETARY DYNAMICS}

\section{Celestial Mechanics}

By E. Finlay-Freundlich. Fp. viii +150 . (London and New York: Pergamon Press, 1958.) 50s. net.

Stability in Celestial Mechanics

By Prof. Yusuke Hagihara. (Jubilee Publication in Commemoration of the Sixtieth Birthday of Prof. Yusuke Hagihara, by his Friends and Pupils.) Pp. $x+106$. (Tokyo: Kasai Publishing and Printing Co., 1957.) n.p. EN years ago it was commonly thought by many
astronomers, most mathematicians and almost
all physicists that celestial mechanics was a dead
subject of historical interest, that it had been worked
out, and that it was unlikely in the future to yield
new results of fundamental importance. The advent
of artificial satellites has led to a re-awalkened
interest in many of the problems of celestial mechan-
ies. It is therefore quite appropriate that new
text-books should be written not only to cater for the
new demand but also so that those unfamiliar with
the subject may become acquainted with the vast
body of knowledge which exists and of which they
might otherwise remain ignorant.
The two books under review are of quite different kinds. Prof. Freundlich's book is a self-contained introduction to the subject. After a brief introductory chapter, the $n$-body problem is discussed, including Lagrange's solutions to the three-body problem, the singularities of the three-body problem and periodic solutions in the neighbourhood of the points of libration. This is followed by an outline of the application of the Hamilton-Jacobi theory, a discussion of the principles underlying perturbation theory, and several discussions on the problems of periodic motions. The book ends with chapters on the two-body problem for extended deformable bodies and on the motion of the apsidal line in relativistic mechanics.

The most surprising feature of the book is the discussion in a relatively elementary way of so many advanced topics, and this is to be commended. It is unfortunate, however, that space was not found for a rather more detailed discussion of some of the basic problems. For example, many university mathematical courses in dynamics end at Lagrange's equations, and proofs of Hamilton's equations and the Hamilton-Jacobi Theorem (without the use of contact transformations) would have added to the value of the book. Also a course on celestial mechanics can scarcely be considered complete if it does not include the equations for the variation of the elements of an orbit. This is, after all, the feature of celestial mechanics of most interest for artificial satellites. Those who, like myself, are frequently charged with the duty of giving formal lecture courses in celestial mechanics, will be grateful to Prof. Freundlich for providing in this text a useful survey of the subject, but they will of necessity supplement this survey with selections from more advanced books to fill the more obvious lacunæ.

Prof. Hagihara's book was published by his friends and pupils to celebrate his sixtieth birthday. $\mathrm{He}$ has attempted to summarize the present situation in the efforts towards solving the very difficult problem of the stability of the solar system. His book ranges widely over many difficult aspects of celestial mechanics, and, by omitting or outlining proofs, he succeeds in giving in a short space an exhaustive survey. He discusses the results of the most advanced research work more completely than any existing text-book or review, and gives comprehensive bibliographies. His book is a land-mark in celestial mechanics.

Neither of the books under review contains any discussion of the numerical problems of celestial mechanics, and it is to be hoped that someone will be stimulated into filling this gap in the literature.

\section{R. H. Garstang}

\section{STEVIN'S MATHEMATICAL WORKS}

The Principal Works of Simon Stevin

Edited by Prof. D. J. Struik. Vol. 2A: Mathematics. Pp. v +1-456. Vol. 2B: Mathematics, Pp. iii + 457-976. (Amsterdam: Swets and Zeitlinger, 1958.) n.p.

THESE two volumes comprise Stevin's principal mathematical works. The first begins with an account of his little known "Tables of Interest" (1582). In a period of rapid commercial expansion, 